in 'it's a good idea'. In fact, to try to boost cognitive performance in this way might be a very bad idea indeed. Would it work? It might or it might not. Nobody knows. All we know for sure is that the technology, known as transcranial direct-current stimulation (tDCS), is likely to soon get into the hands, and onto the heads, of many more people.

Experimentation with electricity to improve human performance is not new. Scribonius Largus, court physician to the Roman emperor Claudius, suggested in AD 46 that a live electric ray could be applied to the head of a patient with a headache. The recent surge in interest in tDCS piggybacks on an increasing number of academic studies of its potential to boost cognitive ability, which themselves build on decades-old work using electrical stimulation of the brain to treat ailments such as depression (see Nature 472, 156-159; 2011).

Nor are unorthodox tests of this technology unusual. When Michael Nitsche, a clinical neurologist at the University of Göttingen in Germany, wanted to investigate a related technique called transcranial magnetic stimulation more than a decade ago, he got permission from university ethics boards but still found a shortage of volunteers. Instead, Nitsche experimented on the brains of himself, his father and his sister.

In an opinion piece published earlier this month, Nicholas Fitz and Peter Reiner of the National Core for Neuroethics at the University of British Columbia in Vancouver, Canada, argue that scientists and regulators can no longer ignore the amateurish meddling with tDCS (N. Fitz and P. Reiner J. Med. Ethics http://doi.org/mv8; 2013). "The challenge for the field," they write, "is to develop policy that thoughtfully deals with the issues stemming from people using tDCS devices at home."

Such home use of experimental laboratory kit puts neuroethicists, and journals such as Nature, in a bind. To draw attention to it could promote and accelerate its use, and so increase the risk of a mishap.
To ignore it leaves the risks unexplored. The scale of at-home tDCS use is unclear at present. It might fizzle out. Or, as scientific interest in the power of electrical stimulation of the brain grows, it might appeal to more enthusiasts, just as the fascination and potential of synthetic biology has spawned a parallel DIY community known as biohackers. The scientific interest is certainly there.

Last month, researchers at the University of Oxford, UK, published a
"The scale of at-home tDCS use is unclear at present." study suggesting that random electrical stimulation of the brain could improve mathematical abilities (A. Snowball et al. Curr. Biol. 23, 987-992; 2013). And there is no lack of exposure. Drawn by the ease of access and the killer copy, science journalists are queuing up to try tDCS for themselves and to write about the effects.

Fitz and Reiner are not the first to raise concerns over the DIY tDCS community. Brain researchers flagged the problem last year, as part of a discussion on the broader ethics of using non-invasive brainstimulation (R. C. Kadosh et al. Curr. Biol. 22, R108-R111; 2012). The researchers even raised the prospect of the ultimate in pushy parents: those who would use the technology on their children to try to boost their cognitive function. And back in 2011, scientists working on tDCS told Nature that they were concerned for the safety of those who tried it at home.

It is easier to raise these questions than to answer them. Fitz and Reiner have some sensible suggestions, ranging from greater reporting of the possible long-term risks of tDCS to mimicking the open communication and education strategy with which the life-sciences field has started to engage biohackers. The first step is to acknowledge the issue to get a sense of how widespread the demand for home electrical self-improvement really is. The next few months will tell us more.

\section{Science prevails}

\section{The US government gives up its fight to keep age restrictions on the morning-after pill.}

\section{A} former senior official at the US Food and Drug Administration (FDA), who is older than 50, recently tried to buy the emergency contraceptive Plan B One-Step (levonorgestrel) at 6:30 p.m. on a Saturday evening in a major metropolitan area. She had to go to three shops before she found one with an open pharmacy, necessitating the use of her car. After waiting in line at the pharmacy, she was required to provide proof-of-age identification and her birth date was entered in a computer. Next, the pharmacist walked the medication to the cashier at the front of the drugstore, where she was obliged to wait in a queue again. When she reached the counter, she had to publicly point out that the emergency contraceptive waiting on the shelf behind the cashier was hers.

If it was this challenging, logistically and socially, for a highly educated scientist to obtain the 'morning-after pill', imagine what it is like for a 17-year-old girl, or an undocumented immigrant or a single mother with no car and no driver's licence.

Happily, these obstacles will soon be things of the past. Last week, the administration of President Barack Obama dropped its legal quest to keep in place a requirement that girls younger than 15 years old obtain a doctor's prescription to buy the one-dose pill - which becomes less effective the longer after unprotected intercourse it is taken. The change makes the drug available to anyone, with no proof-of-age requirement, on open shelves, and not behind the pharmacy counter.

If it makes parents queasy to know that 13- and 14-year-olds will now be able to purchase the pill with no questions asked, two things are worth noting. A paper published in April confirms earlier findings that sex in this age group is rare (L. B. Finer and J. M. Philbin Pediatrics $131,886-891 ; 2013)$. The same paper finds that girls aged 14 or younger are less likely than 15 -year-olds to use contraception the first time they have sex, and that they take longer than older girls to begin using it. Another study found easy access to the morning after pill does not increase promiscuity in the youngest teenagers (C. Harper et al. Obstet. Gynecol. 106, 483-491 (2005).

Nonetheless, there is little comfort to be drawn from the Obama administration's final climb-down on this issue. In a textbook case of political interference in science, successive foot-dragging administrations have for more than 12 years blocked women's and reproductiverights advocates' attempts to win over-the-counter status for Plan B.

During that time, FDA staff scientists and expert advisers repeatedly found that the pill met the agency's requirements for over-the-counter status for women and girls of all ages. Yet, in an unprecedented and deeply worrying action, in 2011 the Obama administration, in the person of health and human services secretary Kathleen Sebelius, overruled its own FDA's decision to lift the age restriction.

That same administration walked away from the case last week not because of any change of heart, but because it saw that it was going to lose before a judiciary that, rightly, has called the government's tactics arbitrary and capricious.

The administration's actions and attitude, coming from a White House that has vowed very publicly to back its scientists, and not undermine them, remain disconcerting. They raise concerns for the future independence of the regulatory scientists who are employed to apply science to existing law.

If this administration, or any White House, has a political issue with $\rightarrow$ NATURE.COM To comment online, click on Editorials at: go.nature.com/xhunqv that law - if, for instance, it wants to enact a bill prohibiting emergency contraceptives for minors - let it do so openly, lobbying for such a measure in Congress. There, and not in the science agencies, is where politics belongs. 